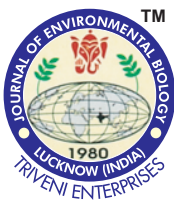

\title{
Rice husk modified cement strength-An environmental approach
}

\begin{abstract}
Authors Info
J. Sathish ${ }^{1 *}$ and P. Selvakumar ${ }^{2}$

'Department of Petrochemical

Engineering, SVS College of

Engineering, Coimbatore-642 109,

India

${ }^{2}$ Department of Chemistry, SVS

College of Engineering,

Coimbatore-642 109, India

*Corresponding Author Email : sthsh35@gmail.com

Edited by

Professor G. Manjula

Reviewed by

Dr. S. Subhagar

Dr. A. Gnanaprakasam

\section{Abstract}

Aim: To improve the life of concrete by surface modifications and to increase hydrophobic nature of concrete by porosity reduction through rice husk coating.

Methodology: Rice husk ash was dispersed in ethanolic solution containing fluoroalkyl silone to prepare super hydrophobic coating. This solution was sprayed on the layer of commercial adhesive coated on the concrete.

Results: Water contact angle of 150.3 was observed on the coated concrete. The cumulative water uptake was reduced up to $40.38 \%$.

Interpretation: Super hydrophobic coating on concrete requires roughness which was created by silica particles in the rice husk. Penetration of water into the coated concrete was successfully reduced, but did not prevent completely. The coating did not affect the surface hardness or the compressive strength, but surface porosity was reduced.

Key words: Hydrophobicity, Modified concrete strength, Porosity, Rice husk

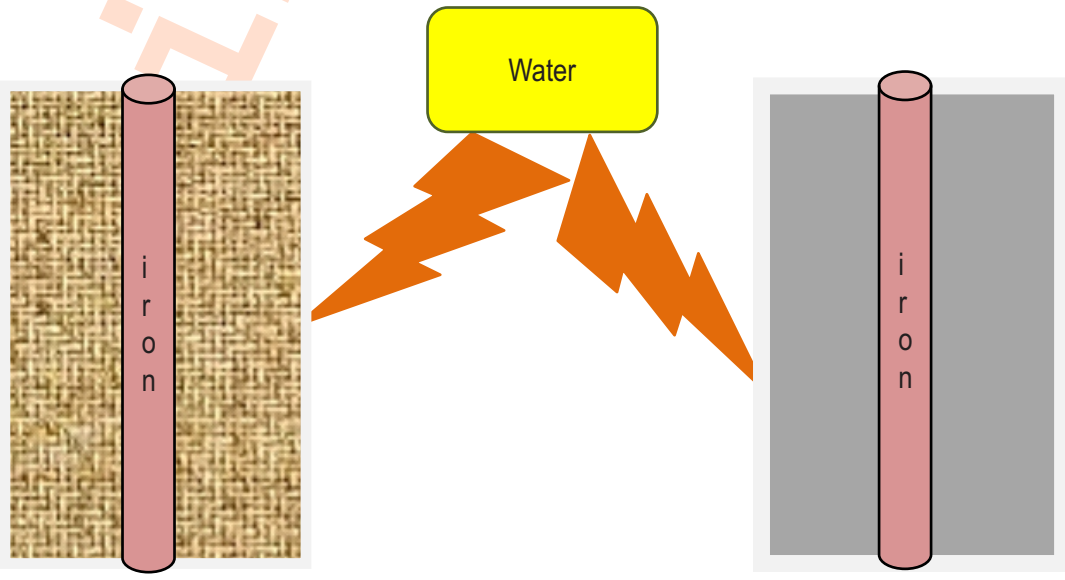

Porous concrete

Rice husk filled concrete pores

How to cite : Sathish, J. and P. Selvakumar: Rice husk modified cement strength-An environmental approach. J. Environ. Biol., 40, 807-811 (2019). DOI : http://doi.org/10.22438/jeb/40/4(SI)/JEB_25
\end{abstract}




\section{Introduction}

Concrete is considered as a strong and resilient material in construction industry, but it suffers loss in strength due to water diffusion into the porous and hydrophilic concrete. Water diffusion not only generates distress in concrete, but also causes corrosion in reinforcement steel because water carries aggressive substances that can cause corrosion of reinforcement steels. Additionally, the rust occupies a greater volume in concrete, resulting in expansion and tensile stress which causes subsequent effects like cracking, spalling and delamination of concrete.

Compounds with silicon-base such as silanes, siloxanes and silicones are commonly employed as water-repellent agents in construction industry (Doran and Cather, 2013). The alkyl groups present in these compounds reduce interaction between concrete and water. In construction industry, the silanes and siloxanes are more commonly used to form the hydrophobic coatings on concrete in order to achieve water proofing. They are applied by dissolving in organic solvents or in water. Silanes are highly volatile and low in viscosity and are usually applied at a minimum concentration of $92 \%$ to prevent aqueous chloride ingress into highway structure (Doran and Cather, 2013). On comparison, siloxanes are less volatile and react faster than silane. Siloxanes application is usually adjusted based on the substrate permeability and pH (Doran and Cather, 2013). The mixture of silanes and siloxanes is also commonly employed instead of using silanes or siloxanes alone. Alternatively, silicone resins with high molecular weight are more frequently used as hydrophobic sealant.

The present construction industry, receives a lot of attention in the application of superhydrophobic coatings and admixtures for construction materials since they offer anti-fouling (Junaidi et al., 2016), anti-corrosion (Tittarelli and Moriconi, 2011) and anti-icing properties (Ramachandran et al., 2016) Besides introducing the hydrophobic agents as mentioned earlier, nanoparticles are commonly used to create the required roughness for superhydrophobic surface (Ahmad et al., 2015). Water penetration of concrete is reduced more than $84 \%$ when superhydrophobic ash is applied on the concrete surface or blended into the concrete before curing. The waste ash has been long used in concrete to replace cement, fine aggregate, coarse aggregate and reinforcing materials partially in order to reduce the building cost and environmental impacts (Prusty et al., 2016). Alkaline ash can be even used for carbon capture and the carbonated ash enhances the mechanical properties of concrete, including tensile and compressive strength (Ekolu, 2016).

In India, about 2 million tons of rice husk are produced annually and burning rice husk is widely practiced for energy generation. The major by-product, rice husk ash contains more than $90 \%$ of amorphous silica which serves as ideal substituent of commercial nanoparticles in the superhydrophobic coating. Ash satisfactorily repels foulant when it is immersed in the slurry solution containing Kaolin and Methylene blue dye (Barbosa et al., 2018). In view of the above, aim of this work was to evaluate the feasibility of superhydrophobic ash coating on concrete to reduce the water absorption of concrete. In addition, the concrete properties such as water contact angle, compressive strength and wall strength were also estimated.

\section{Materials and Methods}

Ordinary Portland cement was used as the main binder in all concrete samples (Ali Nazari, 2012). Fine aggregates should be produced from river sand and sieved using $0.6 \mathrm{~mm}$ sieve, while $20 \mathrm{~mm}$ granite was used as coarse aggregate. Tap water was used for preparing concrete samples and rice husk was used in the preparation of superhydrophobic rice husk ash coating. The concrete sample to be used was prepared by mixing coarse aggregate, fine aggregate, cement and water. Free water/cement fixed ratio was 0.5 .

Burning process is the most important factor in determining the quality of rice husk (Chao-Lung and TrongPhuoc, 2015). Types of burning carried out were as follows.

Open-field burning: Open-field burning process produces low quality rice husk ashes. High crystalline form structure of low reactivity is produced by this process.

Fluidized-bed furnace burning: Combustion heat of rice husk produced by this controlled method of burning is used for electricity generation. It was carried out by maintaining time and temperature. Combustion temperature ranged from $550-700^{\circ} \mathrm{C}$. To remove carbon completely, this process was carried out for longer time or every 1 min temperature was increased to 750 $800^{\circ} \mathrm{C}$. Rice husk ashes having $80-95 \%$ silicon di-oxide, $1-2 \%$ $\mathrm{K}_{2} \mathrm{O}$ and $3-18 \%$ of unburned carbon was produced by fluidized bed furnace. It was also produced by mixing rice husk ash with high cellular structure.

Industrial furnace: This method was used for the environmental and economic reasons. This process gives an efficiency of 90 $95 \%$ silica di-oxide. Rice husk ashes with amorphous silica and

Table 1: Chemical composition of rice husk ash

\begin{tabular}{ll}
\hline Chemical & Composition (\%) \\
\hline Silicon dioxide & 86.94 \\
Aluminium oxide & 0.2 \\
Iron oxide & 0.1 \\
Calcium oxide & $0.3-2.25$ \\
Magnesium oxide & $0.2-0.6$ \\
Sodium oxide & $0.1-0.8$ \\
Potassium oxide & $2.15-2.30$ \\
\hline
\end{tabular}


cellular structure were produced by this method. Highly pozzolanic rice husk ash was created by this method.

Concrete test procedure: As hydrophobic molecules are nonpolar, they prefer other neutral molecules and non-polar solvents. Hydrophobes do not dissolve well in water as, water molecules are polar. When hydrophobic molecules are mixed with water they often cluster together forming micelles. Water present on hydrophobic surfaces will show a high contact angle (Siddique et al., 2016). Water contact angle is used to quantify the hydrophobicity of concrete. Water contact angle is used to quantify the hydrophobicity of concrete. When highly dynamic hydrogen bonds of water are distrupted by non-polar solute an entropic effect refered as hydrophobic interaction originats forming a clathrate-like structure around the non-polar molecules. Water molecules arrange themselves in order to interact with themselves, resulting in highly ordered structure, thus having higher entropic state that cause non-polar molecules to clump together to reduce surface area exposed to water, thus decreasing the entropy of the system. Goniometer (Rame-Hart Instruments co., 250-F1) is used to measure the water contact angle. Water droplets were placed in a coated and uncoated concrete and the water contact angle was measured after $30 \mathrm{sec}$. Values were taken using three concrete samples with three replications of measurement to determine the average value of water contact angle. To conduct the visual inspection on the surface hydrophobicity, water containing methyl orange dye was placed on the surface. Further, the concrete was placed under a tap with running water to demonstrate the water repellence. The samples were tilted to repel water.

Capillary water absorption test: This test was conducted to evaluate the ability of concrete cubes to absorb water by capillary suction. A tray was filled with 2-5 mm depth of water, three concrete samples on two Perspex rods was placed to carry out capillary test.

The surface of concrete samples were sealed with ash coating to avoid water absorption from sides. Ceramic materials have a higher clay content and more porous crystalline structure. Porosity and pore size distributions are important factors that determine both mechanical properties and durability characteristics of hardened concrete. Concrete elements must possess mechanical properties such as intrinsic strength to withstand the stresses to which they are subjected. Durability properties depend on the inherent characteristics of the concrete, the type of environment to which it is exposed and the concrete placement in construction works. Of these three factors, the inherent characteristics of concrete is a factor to be modified and in order to achieve adequate durability control in manufacture of concrete is essential (Guan-Yi et al., 2015).

Rebound hammer test: In this test, hammer hits the concrete at a defined energy. It's rebound is measured by the test equipment and is dependent on the hardness of the concrete (Yehia et al., 2015). The compressive strength is determined by the rebound value. The difference in strength between non-coating and rice husk ash coating surfaces is also obtained by this test. The hammer measures the rebound of a spring-loaded mass impacting against the surface of the sample. The hammer should be held at right angles to the surface while conducting this test. The surface should be flat and smooth.

Ultrasonic pulse velocity test: This test is a nondestructive, insitu test to check the quality of concrete and natural rocks. By measuring the velocity of an ultrasonic pulse passing through a concrete or natural rock formations the strength and quality of concrete rock is determined (Alsayed et al., 2018). Ultrasonic pulse velocity measurement was conducted to investigate the relationship between porosity and strength of the concrete cube samples based on the depth of the void detected. Ultrasonic testing equipment consists of a pulse generation circuit, consisting of electronic circuit for generation pulses and a transducer for transforming electronic pulse into mechanical pulse having an oscillation frequency in range of $45 \mathrm{kHz}$ to $50 \mathrm{kHz}$, and a pulse reception circuit that receives the signal.

\section{Results and Discussion}

Rice husk was burnt and the ash was mixed with concrete. Fourier transform infrared spectroscopy and tests such as hydrophobicity measurement and water repellence test, capillary water absorption test, water penetration test, rebound hammer test, and ultrasonic pulse velocity test were were conducted.

Infrared spectra of samples were recorded using $\mathrm{KBr}$ pellets on a Bruker instrument in the frequency range of 400-4000 $\mathrm{cm}^{-1}$ for the identification of functional groups (Fig 4.1). FTIR was performed for $1 \mathrm{~g}$ of precursor concentration of rice husk ash in concrete. Peaks observed at 1080 and $1600 \mathrm{~cm}^{-1}$ indicated $\mathrm{OH}$ stretching and bending vibrations of adsorbed water. Peak at $1080 \mathrm{~cm}^{-1}$ can be ascribed due to the presence of silica (SI-O-SI stretching and bending vibrations) in the rice husk ash. Peak observed at $1075 \mathrm{~cm}^{-1}$ can be ascribed to the presence of silica (SI-O-SI stretching and bending vibrations) in the rice husk ash. Peak observed around $900 \mathrm{~cm}^{-1}$ corresponded to vinyl C-H out-ofplane bend. Peak observed around $1100-1200 \mathrm{~cm}^{-1}$ aromatic $\mathrm{C}-\mathrm{H}$ in plane bend. The FTIR spectrum of concrete showed a broad peak between $900 \mathrm{~cm}^{-1}$ in the high frequency area together with a sharp peak at $1100 \mathrm{~cm}^{-1}$ corresponding to vinyl C-H out-of-plane bend in the cement. The absorption peaks at $1200 \mathrm{~cm}^{-1}$ corresponds to - aromatic $\mathrm{C}-\mathrm{H}$ in plane bend. Peak observed at $1075 \mathrm{~cm}^{-1}$ can be ascribed due to the presence of silica (Si-O-Si stretching and bending vibrations) in the rice husk ash. Peak observed at $1600 \mathrm{~cm}^{-1}$ indicates the $\mathrm{O}-\mathrm{H}$ stretching and bending vibrations of adsorbed water. On comparing individual IR spectra of cement, rice husk and rice husk modified cement confirmed 


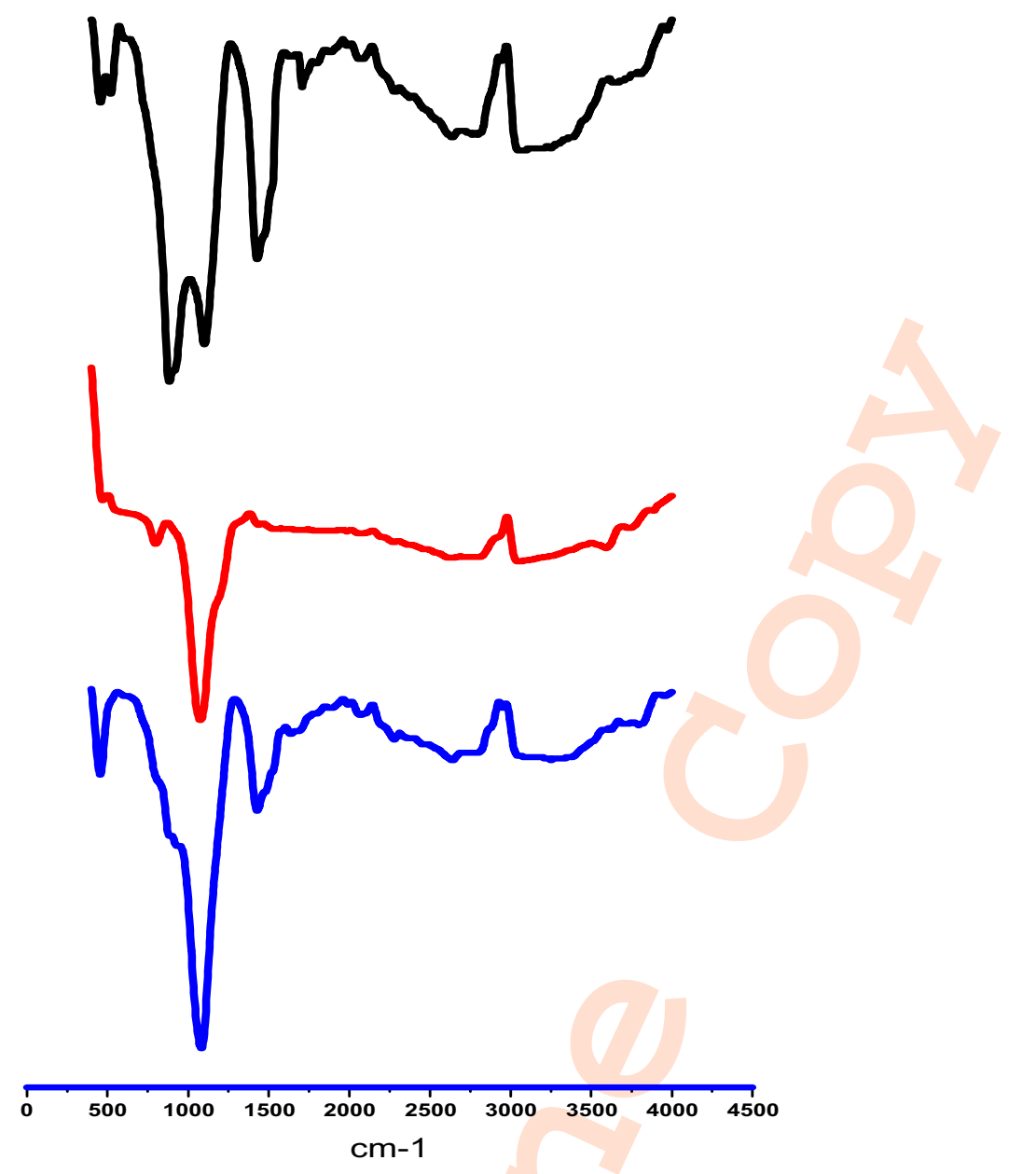

Fig. 1 : FTIR results of (a) concrete (b) rice husk and (c) rice husk+concrete

that the rice husk adsorbed on the surface of concrete forming hydrophobic layer which prevents penetration of water in to it (Satish et al., 2013).

The superhyrophobic surface was successfully formed on the concrete using ethanolic solution incorporated with rich husk ash and fluoroalkyl silane. The concrete surface with the water contact angle of 152.3 I repelled water like lotus leaf. The superhydrophobic coating could reduce the cumulative water uptake as much as $40.38 \%$ (Gill and Siddique, 2017). Penetration of water into the coated concrete under the water pressure of 500 $\mathrm{kPa}$ was successfully reduced, but not fully prevented. Ash coating can be further improved by increasing the number of ash coating or ash content (Kaewkhaoa and Limsuwanb, 2012). Ash coating does not affect the surface hardness or compressive strength significantly (Thomas et al., 2017). On the other hand, ash coating resulted in higher ultrasonic velocity due to reduced surface porosity.
The concrete life has been improved using surface modifications by applying rice husk coating. The coating has been dispersed using ethanolic solution ofRice husk ash containing fluoro-alkyl Silone helps to reduce the porosity of concrete. The cumulative water uptake and Water contact angle observed on the coated concrete confirms the formation of super hydrophobic surface. Though, the penetration was not completely preventable, coating helps to reduce the porosity.

\section{References}

Alsayed, S H. and M. A. Amjad: Strength, water absorption and porosity of concrete incorporating natural and crushed aggregate. J. King Saud Univ. - Enginee. Sci., 8, 109-119 (2018).

Ali, N.: Experimental study and computer-aided prediction of percentage of water absorption of geopolymers produced by waste fly ash and rice husk bark ash. Int. J. Min. Proce., 110-111, 1874-81 (2012).

Thomas, B.S., S. Kumar and H.S. Arel: Sustainable concrete containing palm oil fuel ash as a supplementary cementitious material-A 
review. Rene. Susta. Ener. Rev., 80, 550-561 (2017).

Barbosa, T.R., E.L. Foletto, G.L. Dotto and S.L. Jahn: Preparation of mesoporous geopolymer using metakaolin and rice husk ash as synthesis precursors and its use as potential adsorbent to remove organic dye from aqueous solutions. Ceram. Int., 44, 416-423 (2018).

Chao-Lung, H. and T.P. Huynh: Effect of alkali-activator and rice husk ash content on strength development of fly ash and residual rice husk ash-based geopolymers. Const. Buil. Mater., 101, 1-9 (2015).

Doran, D. and B. Cather: Construction Materials Reference Book. Taylor and Francis, (2013).

Gill, A.S. and R. Siddique: Strength and micro-structural properties of self-compacting concrete containing metakaolin and rice husk ash. Constr. Buil. Mater., 157, 51-64 (2017).

Tittarelli, F. and G. Moriconi: Comparison between surface and bulk hydrophobic treatment against corrosion of galvanized reinforcing steel in concrete. Cem. Concr. Res., 41, 609-614 (2011).

Guan-Yi, C., R. Shan, J.F. Shi and B.B. Yan: Transesterification of palm oil to biodiesel using rice husk ash-base catalysts. Fuel Proc. Technol., 133, 8-13(2015).

Prusty, J.K., S.K. Patro and S.S. Basarkar: Concrete using agro-waste as fine aggregate for sustainable built environment -A review. Int. J. Sust. Built Environ., 5, 312-333 (2016).

Kaewkhaoa, J. and P. Limsuwanb: Utilization of rice husk fly ash in the color glass production. Procedia Engin., 32, 670-675 (2012).

Junaidi, M.U.M., N.N.R. Ahmad, C.P. Leo and H.M. Yee: Near superhydrophobic coating synthesized from rice husk ash: Anti- fouling evaluation. Prog. Org.Coat., 99, 140-146 (2016).

Ahmad, N.A., C.P. Leo, A.L. Ahmad and W.K.W. Ramli: Membranes with great hydrophobicity: A review on preparation and characterization. Sep. Purif. Rev., 44, 109-134 (2015).

Chindaprasirt, P. and S. Rukzon: Strength, porosity and corrosion resistance of ternary blend portland cement, rice husk ash and fly ash mortar. Const. Buil. Mater., 22,1601-1606 (2008).

Ramachandran, R., M. Kozhukhova, K. Sobolev and M. Nosonovsky: Anti-icing superhydrophobic surfaces: Controlling entropic molecular interactions to design novel icephobic concrete. Entropy, 18 (2016). https://doi.org/10.3390/e18040132.

Siddique, R., K. Singh, M. Singh, V. Corinaldesi and A. Rajor: Properties of bacterial rice husk ash concrete. Const. Buil. Mat., 121, 112-119 (2016).

Tulashie, S.K., F. Kotoka, D. Mensah and A.K. Kwablah: Investigation of the compressive strength of pit sand, and sea sand mortar prisms produced with rice husk ash as additive. Const. Buil. Mat., 151, 383-387 (2017).

Ekolu: S.O.: A review on effects of curing, sheltering and $\mathrm{CO}_{2}$ concentration upon natural carbonation of concrete. Constr. Build. Mater., 127, 306-320 (2016).

Satish, H.S., V.S. Vairagadeb and K.S. Kenec: Combine Effect of Rice Husk Ash and Fly Ash on Concrete by $30 \%$ Cement Replacement. Procedia Engineering, 51, 35-44 (2013).

Yehia, S., K. Helal, A. Abusharkh, A. Zaher and H. Istaitiyeh: Strength and durability evaluation of recycled aggregate aoncrete. Int. J. Concrete Str. Mater., 9, 219-239 (2015). 